\title{
A COPA DO MUNDO DA DITADURA OU DA RESISTÊNCIA? COMEMORAÇÕES E DISPUTAS DE MEMÓRIAS SOBRE A ARGENTINA DE 1978i
}

The World Cup of dictatorship or resistance? The commemorations and disputes of memories about Argentina of 1978

¿El Mundial de la dictadura o de la resistencia? Celebraciones y disputas de memorias sobre Argentina de 1978

LÍVIA GONÇALVES MAGALHÃES ${ }^{I^{*}}$

\footnotetext{
'O presente trabalho foi realizado com apoio da Coordenação de Aperfeiçoamento de Pessoal de Nível Superior - Brasil (Capes). Código do financiamento 057.

' Universidade Federal Fluminense (UFF), Niterói - RJ, Brasil.

* Professora adjunta de história do Brasil República do departamento de história e do Programa de Pós-Graduação em História da Universidade Federal Fluminense. (liviagm@id.uff.br), ORCID iD: http://orcid.org/0000-0002-0806-2578

Artigo recebido em $1^{\circ}$ de julho de 2019 e aprovado para publicação em 8 de outubro de 2019.
} 


\section{RESUMO}

0 objetivo deste artigo é relacionar as memórias sobre a vitória argentina na Copa do Mundo de 1978 ao contexto mais amplo de construções e disputas memorialísticas que marcaram tanto a ditadura quanto a redemocratização e a democracia da Argentina. A história recente do país é fortemente marcada pelos conflitos entre o passado autoritário e as relações da sociedade com a última ditadura, que surgem constantemente como espaço de conflito no presente por meio das disputas de narrativas sobre as muitas memórias construídas e consolidadas. A vitória de 1978 é um marco no conflito entre torcer versus resistir ao regime que vigorou entre março de 1976 e dezembro de 1983. Com o respaldo de dados consultados na sede da Federação Internacional de Futebol (Fifa) e de arquivos argentinos, nossa hipótese é a de uma mudança de política governamental com a chegada da direita na figura de Maurício Macri em 2015, em oposição às políticas de memória durante os governos kirchneristas de 2003 a 2015. Com isso, as comemorações dos trinta anos da conquista, em 2008, e dos quarenta anos, em 2018, permitem analisar essas mudanças políticas e perceber uma alteração na perspectiva da Copa como evento da ditadura.

PALAVRAS-CHAVE: Argentina; Copa do Mundo; Celebrações; Ditadura; Memórias.

\section{ABSTRACT}

The aim of this article is to relate the memories of the Argentine victory at the 1978 World Cup to the broader context of constructions and memorial disputes that marked Argentina's dictatorship, redemocratization and democracy. The recent history of the country is strongly marked by the conflicts between the authoritarian past and society's relations with the last dictatorship, which constantly emerge as a space of conflict in the present through narrative disputes over the many memories built and consolidated. The 1978 victory marks a milestone in the conflict between cheering versus resisting the regime that ran from March 1976 to December 1983. Backed up by data consulted at the headquarters of the International Football Federation (FIFA) and Argentine with the coming to power of Mauricio Macri, in 2015, our hypothesis is that of a change in government policy based on memory, something that happened during the Kirchnerist governments from 2003 to 2015. Thus, the commemorations of the 30th anniversary of the conquest in 2008, and the forty 2018 , allow us to analyze these political changes and to perceive a change in the perspective of the World Cup as an event of dictatorship.

KEYWORDS: Argentina; World Cup; Celebrations; Dictatorship; Memories.

\section{RESUMEN}

El objetivo de este artículo es relacionar los recuerdos de la victoria argentina en el Mundial de fútbol en 1978 con el contexto más amplio de construcciones y disputas conmemorativas que marcaron la dictadura, la redemocratización y la democracia de Argentina. La historia reciente del país está fuertemente marcada por los conflictos entre el pasado autoritario y las relaciones de la sociedad con la última dictadura, que constantemente emergen como un espacio de conflicto en el presente a través de disputas narrativas sobre los muchos recuerdos construidos y consolidados. La victoria de 1978 marca un hito en el conflicto entre animar y resistir el régimen que se desarrolló entre marzo de 1976 y diciembre de 1983. Respaldado por datos consultados en la sede de la Federación Internacional de Fútbol (Fifa) y los archivos argentinos, nuestra hipótesis es la de un cambio en la política gubernamental con la llegada al poder de Mauricio Macri en 2015, en oposición a las políticas de memorias durante los gobiernos kirchneristas de 2003 a 2015. Por lo tanto, las conmemoraciones del 30 aniversario de la conquista en 2008, y los cuarenta Los años, en 2018, nos permiten analizar estos cambios políticos y percibir un cambio en la perspectiva de la Copa del Mundo como un evento de dictadura.

PALABRAS ClaVE: Argentina; Mundial; Celebraciones; Dictadura; Recuerdos. 


\section{INTRODUÇÃO}

"Menos democracia, às vezes, é melhor para organizar uma Copa." ${ }^{1}$

frase acima foi dita em abril de 2013 pelo então secretário-geral da Federação Inter-
nacional de Futebol (Fifa), Jérôme Valcke, durante uma das visitas feitas pela entidade ao Brasil para inspecionar os andamentos das sedes da Copa do Mundo masculina de 2014. À época, o que para alguns se justificou como "brincadeira", para tantos outros levantou a questão dos diversos momentos em que a entidade máxima do futebol mundial se viu no centro de denúncias por envolvimento com governos autoritários.

A Copa do Mundo de 1978, realizada na Argentina sob a ditadura civil-miliar (19761983) e vencida pelo país sede, criou, primeiro nacional mas depois internacionalmente, a memória da "Copa da ditadura", mistificando que aquela foi uma conquista do próprio regime, ignorando outras variáveis, atores e realidades que viveram o evento. Como aponta Pablo Albarces (2008), essa foi a principal memória construída pelos meios de comunicação e incorporada tanto pela sociedade quanto pelos meios esportivos após o fim da ditadura, nos primeiros anos da década de $1980 .^{2}$ Desde então, a memória da vitória e da própria Copa incluindo sua organização e seu cotidiano - foram espaços de disputas, acompanhando, de certa forma, a própria memória construída e renovada ao longo de décadas sobre a última ditadura argentina no século XX.

Assim, parece-nos interessante pensar a vitória esportiva de 1978 com base na análise de como lidamos com as "datas comemorativas" em relação aos traumas da história recente. Em geral, são episódios como o dia dos golpes ou algum evento da redemocratização (eleições, posse etc.) que costumam ser considerados nas comemorações. Como destacou Elizabeth Jelin sobre as "datas infelizes", "uma vez instaladas, as marcas e inscrições não estão cristalizadas para sempre. Seu sentido é apropriado e ressignificado pelos diversos atores sociais, segundo as circunstâncias e o cenário político no qual se desenvolveram suas estratégias e seus projetos" (2002: 2, tradução livre). As comemorações futebolísticas impreterivelmente se misturam às festas nacionais, sendo lembradas e celebradas nas décadas seguintes sob diferentes leituras.

Como pensar, no entanto, em termos de construções e disputas de memórias a Copa de 1978 nas comemorações dos trinta e dos quarenta anos do título? Maurice Halbwachs (2006) trouxe o debate da memória como uma experiência coletiva, sem negar a existência da memória individual. 0 autor destaca que é com base no comum da memória coletiva que devemos entender as experiências subjetivas. Paul Ricouer questiona a proposta de Halbwachs 
e aponta que os grupos sociais de fato influenciam memórias individuais, mas essas não são necessariamente pertencentes a tais grupos (Ricouer, 2007). Tais considerações nos parecem importantes para trabalhar as diversas memórias trazidas aqui: meios de comunicação, jogadores e técnico, federações internacionais, organismos de direitos humanos e sociedade civil.

Entendemos que são duas as principais memorias sociais dominantes e em constante disputa na história recente argentina em relação à Copa de 1978. Na primeira, já mencionada, "Copa da ditadura", jogadores, comissão técnica e demais envolvidos no campo de jogo eram vistos como apoiadores da ditadura por terem participado/contribuído para o evento. Essa memória, dominante também num panorama internacional, tornou-se um grande espaço de conflitos, principalmente, como veremos, pela negação dos atletas envolvidos, que reivindicaram ao longo das décadas posteriores sua isenção nas disputas políticas do período e, claro, o destaque da conquista no campo esportivo (Roldán, 2007).

A partir de 2003, com a chegada de Néstor Kirchner à presidência, consolidou-se o que chamamos aqui de uma segunda memória pública dominante, na qual a sociedade aparece não mais como vítima, mas como resistente. Vai ser dessa forma também que passarão a ser entendidas as manifestações positivas nas comemorações da vitória da seleção de futebol, sobretudo a partir das celebrações dos trinta anos, em 2008. Ambas as memórias permaneceram em disputa ao longo das décadas, muitas vezes misturadas e confusas entre si.

A partir de 2015, porém, a interpretação crítica e de sociedade resistente apresentada como oficial durante o período kirchnerista (2003-2015) foi colocada em xeque pelo Estado. Em 2018, com Mauricio Macri na presidência da República — eleito pelo Proposta Republicana (PRO) - , as rememorações dos quarenta anos da Copa foram praticamente desvinculadas do Estado: sem atos oficiais, sem reflexões, um panorama muito diferente de dez anos antes.

Este artigo se divide em três partes. Na primeira, faremos uma breve análise da Copa de 1978, levantando algumas questões que consideramos importantes, como o interesse da ditadura em sua realização. Na segunda, analisaremos o contexto pós-ditatorial e os debates envolvendo as comemorações esportivas em relação às disputas de memórias sobre o passado recente autoritário. Na terceira, consideraremos o ano de 2018, ocasião dos quarenta anos da vitória, que nos parece um interessante marco para pensar lugares, disputas e ressignificações das duas memórias citadas sobre a vitória. 


\section{8: A COPA DA DITADURA?}

$\mathrm{N}$ o dia 6 de julho de 1966, em seu 35 Congresso em Londres, a Fifa escolheu a Argentina como sede de seu evento de 1978. Oito anos depois, após o fim da Copa do Mundo na Alemanha Ocidental, em 1974, a entidade confirmou o país como sede, num momento em que a Argentina entrava em profunda crise política, econômica e social com o falecimento do então presidente, Juan Domingo Perón.

A princípio, o objetivo de María Estela Martínez de Perón — que, como vice, assumiu a presidência após a morte do marido — foi manter a organização. Nos arquivos da Fifa em Zurique há diversos planos de construção e reforma de estádios, além de trocas de correspondências entre a federação internacional e a Associação do Futebol Argentino (AFA). Entre os muitos documentos, há uma carta do então chefe de Relações Públicas da Fifa, Renné Courtes, a um jornalista argentino de maio de 1976, dois meses após o golpe de Estado: "Vamos ver como mudam as coisas na Argentina. Aqui na Fifa nós temos o pressentimento geral de que, com a mudança para o governo militar, as coisas serão mais fáceis para a Fifa do que antes" (Arquivo Fifa, tradução livre). Era a primeira Copa do Mundo organizada por João Havelange desde sua chegada à presidência da federação, em julho de 1974, o que nos ajuda a compreender sua obstinação em entregar um evento considerado de alto nível e de que modo os conflitos internos argentinos eram entendidos como prejudiciais a esse projeto.

De acordo com Daniel Lvovich, o golpe de 1976 representou um momento em que os líderes civis e militares do país estavam de pleno acordo quanto às medidas que deveriam ser tomadas: "destruir as bases da desordem", "liquidar a 'Argentina maldita'" e colocar em prática um projeto de reestruturação e reconstrução da sociedade e da própria nação (Lvovich, 2009). Era esse processo de "refundação nacional", assentado em políticas de Estado baseadas no desaparecimento dos opositores, transformados, então, em "inimigos", que estava em curso durante a realização da Copa.

Em 1978, a imagem internacional da Argentina estava bastante associada às acusações de violação dos direitos humanos, e a atenção que eventos davam ao país significou um importante aumento dessas denúncias. Como aponta Marina Franco (2005), elas eram originárias em grande parte da Europa, onde as principais manifestações vinham de grupos e partidos de esquerda, do governo dos Estados Unidos e da Anistia Internacional. Foram organizados comitês de boicote ao evento, com sede principal na França.

Em seu discurso, os militares denunciavam o que consideravam uma campanha externa contra o país, resultado de um desconhecimento da realidade nacional por parte dos acusadores e de uma ação da subversão externa. Na verdade, a campanha anti-Argentina tratava, em 
primeiro lugar, de uma reatualização de antigas denúncias, existentes desde o primeiro ano do regime e que ganhou força em 1978. Por isso, a principal preocupação do governo era sua imagem externa e sua repercussão internamente. Nesse momento, o governo reconhecia que a subversão interna já estava derrotada, de modo que a nova ameaça era a subversão externa e aqueles que acusavam o regime de crimes de lesa-humanidade (Franco, 2005).

A Copa ocorreu quando o regime se concentrava em medidas de reestruturação nacional, já que as consequências da política econômica ainda não eram visíveis. Logo, apenas ganhar não era importante. Como país sede, os militares puderam utilizar a própria organização do evento como propaganda a seu favor, respondendo a acusações e questionamentos vindos do exterior. Segundo Roldán:

Nesse contexto autoritário, as atribuições de sentidos sobre as práticas futebolísticas foram uma arena de disputa. [...] A Copa de 1978, então, era uma peça chave no quebra-cabeças das relações de poder. Um acontecimento propício para exibir e difundir os valores que a ditadura aspirava estimular na sociedade argentina, recorrendo ao apelo que a contemplação passiva de uma prática esportiva oferece, utilizando um dispositivo apenas indiretamente repressivo (2007: 132, tradução livre).

0 principal ponto de desavença para a sociedade e os membros das Forças Armadas foi o custo financeiro do evento, e um dos mais fortes opositores à realização foi o ministro da Economia à época, José Martínez de Hoz, que garantia que a situação econômica do país não permitia esse tipo de gastos. Por fim, contudo, os militares decidiram pela realização da Copa, pois sabiam os benefícios que poderiam conseguir a realizando no país. Assim, em 2 de julho de 1976, foi criado o Ente Autárquico Mundial 78 (EAM 78), responsável pela organização do evento. Nas disputas internas entre Exército e Marinha, foram os segundos quem de fato controlaram o organismo, por intermédio do vice-almirante Carlos Lacoste (Magalhães, 2014).

A questão dos altos gastos do evento argentino em infraestrutura e divulgação nos interessa aqui porque seriam posteriormente um dos primeiros pontos de crítica e de uma memória negativa. 0 decreto de lei $n^{\circ} 21.349$, que criou o EAM 78, também indicava as origens dos gastos disponibilizados para tal organismo e a organização da Copa. ${ }^{3}$ A construção de três novos estádios e a remodelação de outros três, ${ }^{4}$ a criação de um centro de imprensa, os investimentos em tecnologia para a transmissão a cores etc. foram feitos pelo EAM 78 praticamente sem controle oficial, e "a distribuição dos fundos do EAM 78 era decisão da própria entidade, que não precisava prestar contas sobre suas decisões, (...) o que ajuda a entender o elevado custo final que teve o evento para o Estado argentino: 700 milhões de dólares, segundo os meios de comunicação da época" (Magalhães, 2014: 73). 
Em 1982, após a Copa do Mundo da Espanha, o ex-Ministro Roberto Teodoro Alemann não hesitou em afirmar que o valor fora ao menos dez vezes maior do que o proposto incialmente, e que, em comparação com a Copa de 1982, "custou ao governo espanhol mais ou menos quinze bilhões de pesetas, apesar de ter sido quatro anos depois" (El País, 2/9/1982, tradução livre).

Com a vitória, a comoção nacional foi intensa. No discurso do presidente Jorge Rafael Videla, a conquista simbolizava uma nova etapa do projeto ditatorial vencida pelas Forças Armadas. Como aponta Archetti: "A Copa do Mundo se tornou um sucesso numa sociedade 'pacificada'. As manifestações de alegria nos estádios e nas ruas após as vitórias argentinas que culminaram no triunfo contra a Holanda na final foram interpretadas pela junta como um sucesso de um projeto nacional" (2006: 37, tradução livre).

Vencendo dentro de casa e gerando emoção popular, o governo argentino não deixou de associar o êxito esportivo ao seu próprio projeto. Pode-se indagar se realmente não foi o regime civil-militar o grande vencedor. Com a realização do evento e a vitória da seleção, as Forças Armadas conseguiram melhorar temporariamente sua imagem interna e renovar, também por um tempo, o consenso dentro do país. Além disso, mesmo com o aumento das denúncias contra a violação de direitos humanos no país - e com a visita da Comissão Interamericana de Direitos Humanos (CIDH) da Organização dos Estados Americanos (OEA) em 1979 e as duras críticas feitas ao regime — , houve uma mudança momentânea na imagem da Argentina no exterior.

A principal razão para isso foram os testemunhos positivos de esportistas e jornalistas que participaram do evento. Já dentro do país, declarada a vitória na guerra contra a subversão interna, o governo conseguiu uma considerável mobilização das massas populares a seu favor, e os meios de comunicação que apoiavam o projeto oficial tiveram um papel fundamental nessa associação entre o sucesso na área esportiva e o modelo da ditadura.

É preciso, no entanto, ter cuidado ao limitar essa interpretação, diretamente associada ao que apontamos no início deste trabalho, como primeira memória dominante da vitória. Mas é inquestionável o significado político que ganhar a primeira Copa do Mundo em casa teve para um regime que sofria com acusações graves de práticas de crimes de lesa-humanidade.

A partir de 1983, com a redemocratização, a memória dominante foi de reprovação da ditadura, e a crítica à vitória esportiva está relacionada a isso. Durante anos, como vimos, condenaram-se tanto o evento quanto jogadores, comissão técnica e torcedores. Para muitos, era uma vergonha assumir ter participado das celebrações, que ganharam uma conotação quase tão negativa quanto a ditadura. 
Johann Michel, ao tratar da construção de memórias e narrativas por parte de poderes públicos, aponta que elas "se orientam a supostamente unir membros de uma sociedade ao redor de uma história comum, mesmo se essas configurações narrativas dizem mais sobre a maneira pela qual o poder se coloca em cena e seus valores do que propriamente sobre a memória coletiva sobre a qual supostamente se apoiaria" (2010: 15). Torna-se fundamental, portanto, acompanhar como se deram as disputas memorialísticas sobre a ditadura na transição e no novo período democrático a partir de 1983, percebendo, assim, se de fato as muitas memórias da vitória em campo acompanharam ou não esse processo e seus conflitos.

\section{DEMOCRACIA, FUTEBOL E MEMÓRIAS}

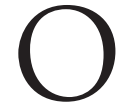

principal diferencial do processo de redemocratização argentino foi o foco dado à questão judicial (Jelin, 2008). Assim, a Argentina iniciou sua volta à democracia construindo também um referencial para a questão na América do Sul e, por que não, em todo o mundo. Raúl Alfonsín, advogado e membro da Assembleia Permanente pelos Direitos Humanos - um dos principais meios de denúncia da violência estatal no período ditatorial — , foi eleito pela União Cívica Radical o primeiro presidente democrático, assumindo o cargo em 10 de dezembro de 1983 - não por acaso, dia internacional dos direitos humanos.

De início, na transição da ditadura e no novo período democrático, a memória coletiva que prevaleceu foi a de uma sociedade vítima da violência resultante do antagonismo e do conflito entre duas forças políticas, guerrilheiros e militares, que resultou na violência física, na forma da violação de direitos humanos de vítimas dessa mesma sociedade "inocente". Conhecida como "teoria dos dois demônios", trata-se da concepção que aparece no informe final da Comissão Nacional sobre o Desaparecimento de Pessoas (Conadep): a de que a violência política que marcou a década de 1970 e o último regime civil-militar na Argentina foi resultado das ações dos responsáveis das Forças Armadas e dos grupos guerrilheiros. Apesar de críticas por parte de organizações de direitos humanos e pesquisadores, tal interpretação ainda é bastante forte no imaginário social argentino (Franco, 2014).

Em abril de 1984, após a dificuldade, pelas Forças Armadas, para iniciar os julgamentos de seus membros, determinou-se o julgamento civil aos militares acusados de crimes não militares. Os julgamentos começaram em abril de 1985, no governo de Alfonsín. Foram a julgamento as três primeiras juntas militares, em audiências públicas, com 833 testemunhos, entre 22 de abril e 14 de agosto de $1985 .{ }^{5}$ A sentença determinou que a terceira junta, que governou depois de 1980, era inocente, enquanto os membros das juntas anteriores foram condenados a diferentes penas, entre elas prisão perpétua para o general Jorge Rafael Videla e 
o almirante Emilio Eduardo Massera, e dezessete anos de prisão para o general Roberto Viola (Jelin, 2008). Para Alabarces, é nesse contexto que

começa a transformar-se em uma metáfora do ocultamento e do silêncio, diante de (...) seu símbolo como jubileu, festejo e unitarismo no momento de sua realização.

(...) É o que demonstra a reiterada transmissão das imagens da Copa em fragmentos de filmes da transição democrática: qualquer televisão ligada que quisesse representar esse momento mostrava essas imagens, definindo rapidamente todo o período ditatorial (2008: 120-121: 125, tradução livre).

Entre os anos de 1987 e 1990, ocorreram diversos levantes militares, que ameaçavam a recém-instaurada democracia. Ao procurar controlar as tensões sociais e evitar a radicalização dos movimentos militares, o presidente Raúl Alfonsín criou a Lei do Ponto Final, de 24 de dezembro de 1986, e, posteriormente, a Lei de Obediência Devida, de 4 de junho de 1987, conhecidas popularmente como "leis da impunidade". As leis determinavam, respectivamente, uma data limite para novos processos judiciais contra os acusados de violações aos direitos humanos na época da ditadura militar, bem como que os feitos cometidos pelos membros das Forças Armadas no período da guerra suja e do processo de organização nacional não eram puníveis, pois os acusados teriam atuado em virtude de obediência devida.

Tais leis, todavia, não invalidavam o Julgamento das Juntas; somente pretendiam limitar o processo de punição à alta elite das Forças Armadas e do governo civil-militar, como punição exemplar, para evitar uma crise institucional no país. Portanto, elas não excluíam os casos dos militares já condenados - como faria posteriormente o governo de Carlos Saúl Menem mas evitavam o castigo a subordinados e a outros responsáveis (Jelin, 2008).

Frente às crises política e econômica que marcaram o período, Raúl Alfonsín renunciou, em 1989, e antecipou-se a posse de Carlos Menem como novo presidente argentino. Entre 1989 e 1990, Menem declarou os indultos aos militares e o perdão aos autores de crimes de lesa-humanidade que não foram beneficiados pelas leis anteriores do governo Alfonsín. Dessa forma, os julgamentos iniciados em 1984 foram definitivamente paralisados. A partir desse momento, a brecha legal para as organizações de direitos humanos e demais grupos que insistiam na condenação dos acusados por crimes de lesa-humanidade no período ditatorial foi a apropriação ilegal dos bebês das prisioneiras por parte dos militares. ${ }^{6}$

Segundo Pablo Alabarces (2008), tanto a organização da Copa de 1978 quanto a primeira conquista da seleção nacional argentina são parte importante dessas disputas de memória. Ao longo das décadas o evento foi repensado, revivido e rememorado de diversas formas. Em 
1988, por exemplo, a sociedade argentina preferia celebrar sua segunda vitória em Copas do Mundo, a de 1986, no México. 0 bicampeonato teve muitos significados no contexto de redemocratização do país: a vitória contra a Inglaterra quatro anos após a derrota militar na Guerra das Malvinas e, sem dúvidas, a construção do mito do jogador Diego Armando Maradona.

A conquista de 1986 substituía também a vitória envergonhada de 1978 na glória esportiva, como aponta Alabarces: "Os discursos da invenção da pátria ou da crise da pátria tornam-se experiências, de prazer ou de dor. É o que acontece com as celebrações da Copa de 1986 - que também celebravam a democracia e indicavam, no mesmo gesto, a visão negativa da ditadura" (2008: 14-15, grifos no original, tradução livre). Era uma conquista inquestionável, sem a "mancha de sangue" que marcava, naquele momento, 1978.

Em 1998, no aniversário de vinte anos, o país vivia, como vimos, um período quase de silêncio em relação ao seu passado recente, que incluiu os próprios festejos da primeira Copa, ainda lida principalmente como uma parte mais da ditadura.

\section{DO KIRCHNERISMO AO "CAMBIEMOS"7}

década de 2000 foi de importantes e intensas mudanças na sociedade argentina. Com
o esgotamento do modelo neoliberal e da década presidencial de Carlos Menem, que governou o país entre 1989 e 1999, a Argentina enfrentou, nos anos de 2001 e 2002, sua pior crise econômica, o que levou a uma grande crise social e política. Manifestações com gritos de "Que se vayan todos" representavam a insatisfação da população e a possibilidade de repensar as últimas décadas e suas consequências. Foi nesse ambiente, com a eleição de Néstor Kirchner, em 2003, que o tema dos julgamentos aos militares foi retomado.

Em seu discurso de posse, Kirchner consolidava como políticas públicas grande parte das demandas das principais organizações de direitos humanos (Calado, 2011). 0 recém-eleito presidente enviou, ainda em 2003, um projeto de lei ao Congresso, propondo a anulação das leis anteriores, favoráveis aos militares. Em 2001, o juiz federal Gabriel Cavallo declarara as leis de Ponto Final e de Obediência Devida inconstitucionais e inválidas num caso particular. A sentença foi confirmada pela Corte Suprema em 2005, o que significou a reabertura de centenas de processos.

Em 2006, foram considerados inconstitucionais os indultos de Menem. No mesmo ano, de aniversário dos trinta anos do golpe de 24 de março de 1976, com a reabertura dos julgamentos contra os acusados de violação de direitos humanos na última ditadura, o debate sobre a memória do passado recente argentino ganhou novo fôlego. 
Os 25 anos da vitória de 1978 coincidiram com a chegada de Kirchner ao poder, e nessa data comemorativa ainda prevaleceu, de acordo com Alabarces (2008), principalmente o discurso da influência da ditadura na Copa, relativizando-se o valor da conquista. 0 autor, todavia, mostra que parte dos jogadores campeões já começavam a se manifestar, buscando mudar a memória dominante de associação entre a equipe e a ditadura: "Da mesma forma, alguns jogadores envolvidos na organização de uma festa de comemoração (...) procuraram saldar a dívida futebolística, incluindo e homenageando os Organismos de Direitos Humanos no estádio do River Plate" (125-126, tradução livre). ${ }^{8}$

Nesse contexto, abriu-se espaço para o debate crítico sobre o passado recente ditatorial, que havia enfraquecido no período menemista. Em 2007, Cristina Fernandez de Kirchner, esposa de Néstor, foi eleita presidenta e deu continuidade ao projeto iniciado no governo anterior, consolidando a "nova" memória do Estado sobre o passado recente. ${ }^{9}$ É preciso, pois, entender tanto as comemorações dos trinta anos do golpe de logo depois os trinta anos da conquista futebolística como parte de um contexto amplo de reformulação de políticas e lutas de memória no país.

É curioso incluir aqui as mudanças no discurso feitas pela Fifa em relação à Copa de 1978 ao longo dos anos. Num primeiro momento, logo após o evento, o presidente João Havelange não poupou elogios à organização argentina e tampouco escondeu sua simpatia à ditadura: "Após mudanças políticas e econômicas no país, a criação do Ente Autárquico Mundial, com o árduo trabalho do admirável Carlos Alberto Lacoste como responsável, o apoio recebido pelas autoridades argentinas e a excelente cooperação entre o EAM, a AFA e o comitê organizador da Fifa [...], tivemos uma organização quase perfeita da Copa do Mundo da Fifa de 1978 (Relatório Final Copa de 1978: 4, Arquivo Fifa, Zurique).

Em outra obra oficial da entidade, algumas décadas depois, comemorando seus cem anos em 2004 e sob a presidência de Joseph Blatter, percebemos a mudança no discurso: "As televisões mostraram as imagens do técnico argentino César Luis Menotti negando-se a receber a taça das mãos de Videla, e a equipe holandesa que não aceitou os cumprimentos do general pelo vice campeonato" (Eisenber, Lanfranchi e Mason, 2004: 289, tradução livre).

Interessa-nos aqui, principalmente, a visão de resistência por parte dos atletas, que naquele cenário não teriam se submetido aos representantes do regime nas celebrações. Diferentemente do publicado, Menotti não se negou a receber o troféu em 1978. Durante muito tempo, o ex-técnico foi acusado de ter ajudado a ditadura e até de ser um homem de interesse dos militares, motivo pelo qual foi mantido no cargo. ${ }^{10}$ Durante a Copa de 1982, quando perguntado sobre seu papel em 1978 e o posterior uso da vitória pelo Processo, Menotti foi firme: "Eu me preocupei com que a equipe divertisse as pessoas [...] fiz todo o possível dentro das 
minhas possibilidades. Além disso, sabe o que é preciso diferenciar? Eu sou um trabalhador, cara... não sou um fator de poder" (El Porteño, 1982: 15, tradução livre).

Anos depois, no documentário comemorativo dos trinta anos do título La historia paralela, lançado em 2008, ao ser indagado sobre o lugar que a seleção ocupou na ditadura e o sentido que a Copa teve para o regime e para o apoio da sociedade, o mesmo Menotti considerou que "não era a Junta Militar, não era o público do River, eram as pessoas de José Carlos Paz, as pessoas dos povoados, as pessoas que desciam dos caminhões, dos táxis, e não nos deixavam passar" (tradução livre). ${ }^{11}$

Tal reflexão deve ser compreendida no contexto de releitura da participação dos jogadores, na lógica de uma sociedade que resistiu em todas suas esferas. Para muitos dos atletas envolvidos, essa releitura e a transformação numa memória dominante e oficial foi um importante momento de fazer as pazes com a sociedade e com seu passado, a pesar de, em 2018, ainda destacarem a permanência de uma visão negativa da conquista:

A voz do goleador da Copa de 1978 é a do grupo de jogadores que se sente desprezado. Esquecido. Convive com a impressão de que a estrela conquistada no México em 1986 brilha mais do que a da Argentina de 1978. Repito em coro que o objetivo era um só: "Trazer alegria ao povo", e que eles não sabiam da gravidade do que acontecia no país, a poucos metros do estádio Monumental onde o Matador estava transformando-se em herói (tradução livre).12

Assim, até 2015, a memória oficial do governo argentino era a dos organismos de direitos humanos. Mas estavam presentes também, lutando por um espaço na esfera pública, grupos que se afirmam "vítimas do terrorismo", ou seja, os que lutam por uma memória positiva da ditadura. Foi no contexto de luta entre os sentidos do passado e das memórias sobre ele construídas (Jelin, 2008), com a associação feita entre a memória oficial do kirchnerismo sendo a da crítica à ditadura, que atores políticos da oposição começaram a se posicionar baseados em sua problematização. Foi nesse espaço de conflito que o projeto PRO e seu principal nome, Mauricio Macri, conseguiram se projetar como opção ao peronismo oficialista.

Macri é um empresário argentino, que se tornou conhecido do grande público em 1991, quando foi sequestrado e mantido em cativeiro por doze dias, até o pagamento de um resgate. Em 1995, foi eleito presidente do Club Atlético Boca Juniors, cargo que ocupou até 2007, quando foi eleito governador de Buenos Aires, já pelo PRO. ${ }^{13} \mathrm{~A}$ partir de então, tornou-se 0 principal nome de uma renovada direita argentina, que se posicionava principalmente como outsider do modelo político tradicional. Sua reeleição na capital federal, em 2011, confirmou essa liderança, e em 2015, apesar de uma campanha que começou desacreditada por muitos, Macri foi eleito presidente. 
Às vésperas dos quarenta anos da vitória de 1978, o governo nacional estava envolvido em polêmicas, mas nenhuma delas relacionada ao mundo esportivo. Por um lado, havia o agravamento da crise econômica e social, em especial pelo contínuo aumento da inflação e pelas críticas após o fim dos subsídios às tarifas de água, luz e gás decretados em novembro de 2017. Por outro, havia as crescentes manifestações a favor e contra o projeto de lei de descriminalização do aborto no país. Talvez, para um político que ganhou fama principalmente como dirigente esportivo de um clube de futebol de popularidade mundial, comemorar e relembrar uma vitória como a primeira Copa do Mundo FIFA fosse não só um espaço seguro, mas um caminho para tentar desviar as crises que o governo enfrentava. Ao contrário, Macri optou pelo silêncio da presidência nacional em relação à memória referente ao período autoritário.

Se o governo nacional optou por não incorporar em seu discurso a celebração dos quarenta anos da Copa, as organizações de direitos humanos - em sua grande maioria críticas a Macri — fizeram as próprias celebrações e reflexões. ${ }^{14}$ Assim, ocupavam um vazio, antes sob a liderança do governo kirchnerista e de suas políticas públicas de memória crítica à ditadura. De fato, não foram tantas ações e atividades como nos trinta anos, o que é compreensível quando se retira o Estado das organizações e considerando a crise econômica. Mas é interessante olhar para o que foi feito, levando em conta que a decisão de não esquecer é parte de uma luta política por memória.

A principal das ações não oficiais de rememoração foi o projeto "Papelitos - 78 historias de un Mundial en dictadura". Com duas exposições, uma visita guiada a um espaço de memória e um portal mantido on-line e de livre acesso, foi organizada pela instituição Memoria Abierta e pela Revista Digital NAN, com 0 apoio da Embaixada da Holanda na Argentina. ${ }^{15}$ Com o slogan " ¡Tiren papelitos, muchachos!", ${ }^{16}$ o portal reúne 78 histórias diversas — entre atletas, militantes políticos, sobreviventes, familiares e outros - , com base em depoimentos e material de pesquisa no acervo de distintas instituições de memória argentinas.

0 nome dado ao projeto já demonstra a intenção de retomar (ou seria reafirmar?) o debate de memória que apareceu no segundo momento que apontamos aqui: as comemorações de 2008. Segundo a explicação dada na página oficial, jogar papéis picados quando a seleção entrava em campo surgiu como prática comum dos torcedores argentinos na Copa de 1978 e ia diretamente contra a imagem que a ditadura buscava transmitir: a de um parâmetro de educação e civilidade que não comportava esse tipo de reação.

Durante o evento, alguns radialistas que apoiavam o regime criticaram a atitude dos torcedores. O caricaturista Caloi, ao contrário, usou seu espaço no jornal Clarín para estimular a manifestação, por intermédio de seu popular personagem Clemente. ${ }^{17}$ Dando continuidade 
ao discurso que foi apresentado em 2008, a festa da torcida, o que antes era lido como apoio ao regime, aparece como resistência a uma ordem da ditadura.

O portal também reafirmou o lugar dos jogadores e do técnico Menotti nas muitas memórias críticas à associação entre seleção e ditadura. 0 projeto "Papelitos" procurou Mario Kempes, o maior goleador da Copa de 1978, e o técnico do grupo para que, novamente, deixassem seu depoimento sobre a conquista. Nessa oportunidade, destacou-se o posicionamento político de Menotti, reivindicando sua consciência sobre parte da violência do regime:

Esta formação fez com que o técnico estivesse ciente da realidade que a Argentina vivia durante a ditadura, mas ele esclarece: "Eu sabia que havia detidos e presos políticos. Mais do que isso, eu me comprometi e ajudei em muitos momentos, que não são conhecidos e nem me interessa dizer. Mas eu não imaginava, por exemplo, que atiravam pessoas dos aviões ou as tantas outras atrocidades que ficaram conhecidas depois com o passar do tempo". (tradução livre)..$^{18}$

Por sua vez, Kempes, como vimos, trouxe um discurso consonante com os primeiros anos da redemocratização: "Kempes se lembra com orgulhos aqueles dias, mas logo aparecem em sua mente sentimentos contraditórios. "Nós não somos respeitados. 0 que nós fizemos não era para os políticos que estavam no palco, nós fizemos pelo futebol argentino e pelo povo. Não sabíamos o que estava acontecendo" (tradução livre). ${ }^{19}$ Como aponta Halbwachs (2006), a memória é sempre um produto social, e, como tal, só pode ser compreendida se compreendemos os grupos que a rememoram. Assim, é importante considerar tais testemunhos de jogadores com base na compreensão de que

as entrevistas com os participantes nos festejos estão marcadas pela distância temporal, o que na história argentina significa estar atravessado pela consciência da ditadura. Não há quem possa evitar essa marca: lembrar os festejos significa imediatamente comentários como "não sabíamos o que estava acontecendo", "fomos usados" (Alabarces, 2008: 123, tradução livre).

\section{CONSIDERAÇÕES FINAIS}

$\mathrm{D}$ urante muitos anos, a memória que permaneceu sobre a associação entre esporte e poder foi a do uso negativo do desporto a favor de interesses políticos, e a abordagem mais comum feita sobre a relação entre esporte e política é relacionada ao seu uso por governos autoritários como forma de legitimação, propaganda política e busca de consenso. Foi assim, por exemplo, nos casos da Copa do Mundo da Itália em 1934 e dos Jogos Olímpicos 
de Berlim em 1936, eventos que se tornaram referência nas análises sobre as relações entre esporte e política, cultivando uma imagem negativa dessa relação. No entanto, como aponta Roldán, "o maniqueísmo de um futebol com conotação positiva ou negativa mantém uma dicotomia pouco útil para a reflexão, já que em ambos os casos trata-se de uma perspectiva que substancializa a prática esportiva, colocando-a fora da história e das relações sociais que a produzem" (2007: 127, tradução livre).

Como vimos, as muitas memórias construídas e disputadas sobre a vitória argentina na Copa de 1978 mostram a importância de entendê-las em seus contextos históricos e sociais. Da mesma forma, é fundamental pensar o papel dos testemunhos nessas disputas memorialísticas, pois, como aponta Betriz Sarlo, "o discurso da memória, transformado em testemunho, tem a ambição da autodefesa; quer persuadir o interlocutor presente e assegurar-se uma posição no futuro; justamente por isso também é atribuído a ele um efeito reparador da subjetividade" (2007: 54).

O ex-técnico e campeão mundial César Luís Menotti, em entrevista para o projeto "Papelitos", destacou a associação negativa entre os campeões e a ditadura, que marcou - e, em alguns espaços, ainda prevalece — por tanto tempo as interpretações sobre a Copa: "Não, com certeza não. Foi uma infâmia. Uma infâmia miserável daqueles que depois se dizima revolucionários, mas durante a copa de 1978 transmitiam os jogos com Videla ao lado. Uma vergonha. Realmente é uma vergonha não reconhecer tudo o que esses jogadores fizeram". (tradução livre) ${ }^{20}$

Também nos interessam aqui as disputas e os discursos produzidos e difundidos pelos meios de comunicação. Em 2008, nas movimentações dos grandes atos em comemoração aos trinta anos da Copa do Mundo, o jornal Clarín, um dos grandes conglomerados de comunicação da Argentina — que apoiou a ditadura e foi grande beneficiado das políticas econômicas do período —- deu destaque ao evento organizado pelo Instituto Espaço para a Memória, da cidade de Buenos Aires, um jogo de futebol nomeado "A outra final, o jogo pela vida e pelos direitos humanos". Segundo a organizadora e ex-presa e desaparecida durante a última ditadura Ana María Careaga,

o evento que organizamos para o dia 29 de junho, no estádio do River, é a final que deveria ter acontecido, a final em democracia. É uma homenagem-desagravo à sociedade argentina em seu conjunto. Convidamos os jogadores daquela seleção e também jovens que representarão a geração que não está mais aqui..21

Era um momento de reconciliação entre a sociedade e seus tão questionados heróis de chuteiras. 0 encontro no campo que ocorreu na final trinta anos antes, sob um viés crítico do 
uso político do evento pela ditadura, procurava questionar a memória que associava os atores envolvidos na conquista a um suposto apoio ao regime. A própria Copa se tornava, nessa lógica, uma vítima da ditadura.

Já em 2018, a manchete do mesmo jornal foi: "A emoção da lembrança 40 anos depois da Copa do Mundo de 1978. A memória não esquece que o êxito final da Seleção combinou 0 alívio das pessoas no país com a utilização planificada de parte da ditadura militar." ${ }^{22}$ Os dez anos de diferença entre as duas reportagens apresentadas mostram que, de fato, consolidou-se uma interpretação mais positiva do significado da vitória em 1978, mas, ao mesmo tempo, ainda é espaço de questionamento a politização dessa conquista como parte de uma resistência política ao autoritarismo.

Quanto ao posicionamento oficial da presidência argentina em 2018 de não celebração dos quarenta anos da primeira vitória mundial, a análise de Calveiro sobre as disputas de memória também nos interessa: "No nível das nações promove-se a evaporação da esfera pública, a despolitização da sociedade, e tende-se à fragmentação e destruição de toda forma de organização coletiva" (2006: 380, destaques no original, tradução livre).

É com base nesse discurso de despolitização, de outsider, que o PRO se colocou no cenário político argentino. Assim, entendemos aqui que a não comemoração — ou ao menos a não liderança das comemorações — pelo Estado argentino aos quarenta anos da Copa de 1978, depois dos diversos eventos realizados dez anos antes, que reconstruíram a memória da vitória, colocando-a diretamente relacionada às resistências sociais à ditadura e à sua crítica, é parte do discurso apolítico do governo Macri.

A conquista de 1978, incorporada à memória dominante de crítica à ditadura, não foi incluída nos entendimentos do macrismo como políticas de comemorações. Isso nos permite afirmar que a movimentação em torno das comemorações críticas aos trinta anos tanto do golpe quanto da vitória futebolística consolidaram-se de tal forma que, dez anos depois, se tornaram um lugar de associação ao modelo político do kirchnerismo. Ao mesmo tempo, ficou claro que a memória das organizações de direitos humanos deixou de ser a memória do governo, mas não deixou de marcar seu lugar nas constantes disputas, evitando o silêncio sobre o evento em seus quarenta anos. 
A COPA DO MUNDO DA DITADURA OU DA RESISTÊNCIA?

COMEMORAÇÕES E DISPUTAS DE MEMÓRIAS SOBRE A ARGENTINA DE 1978

\section{NOTAS}

1 "Menos democracia, às vezes, é melhor para organizar uma Copa". Disponível em: http://globoesporte. globo.com/futebol/copa-do-mundo/noticia/2013/04/valcke-menos-democracia-vezes-e-melhor-para-organizar-uma-copa.html. Acesso em: em 10 jun. 2018.

20 tema foi amplamente debatido por diversos autores, como Achetti, em Fútbol: imágenes y esteriotipos (1999); Alabarces, em Fútbol y patria (2008); Roldán, em La espontaneidad regulada (2007); Franco, em Derechos humanos, política y fútbol (2005); Frydenberg e Daskal, em Fútbol, historia y política (2010); Gotta, em Fuimos campeones (2008); Llonto, em La vergüenza de todos (2005), Magalhães, em Com a taça nas mãos: sociedade, Copa do Mundo e ditadura no Brasil e na Argentina (2014).

3 Lei 21349, de 2 de julho 1976. Disponível em: www.infoleg.gov.ar. Acesso em: 4 abr. 2019.

4 Foram construídos os estádios Olímpico, em Córdoba, Mundialista, em Mar del Plata, e Ciudad de Mendoza, em Mendoza. Além disso, foram reformados os estádios Monumental de Nuñez e José Amalfitani, ambos em Buenos Aires, pertencentes, respectivamente, ao Club Atlético River Plate e ao Club Atlético Vélez Sarsfield, e Gigante de Arroyito, em Rosario, pertencente ao Club Atlético Rosario Central.

5 Foram quatro as Juntas Militares que governaram a Argentina entre 1976 e 1983: Primeira Junta Militar de Governo (1976-1979) - tenente general Jorge Rafael Videla, comandante em chefe do Exército argentino; almirante Emilio Eduardo Massera, comandante em chefe da Marinha da República argentina; brigadeiro general Orlando Ramón Agosti, comandante em chefe da Força Aérea Argentina. Segunda Junta Militar de Governo (1979-1981) — tenente general Roberto Eduardo Viola, comandante em chefe do Exército argentino; almirante Armando Lambruschini, comandante em chefe da Marinha da República argentina; brigadeiro general Omar Domingo Rubens Graffigna, comandante em chefe da Força Aérea argentina. Terceira Junta Militar de Governo (1981-1982) — tenente general Leopoldo Fortunato Galtieri, comandante em chefe do Exército argentino; almirante Jorge Isaac Anaya, comandante em chefe da Marinha da República argentina; brigadeiro general Basilio Arturo Ignacio Lami Dozo, comandante em chefe da Força Aérea argentina. Quarta Junta Militar de Governo (1982-1983) — tenente general Cristino Nicolaides, comandante em chefe do Exército argentino; almirante Rubén Óscar Franco, comandante em chefe da Marinha da República argentina; brigadeiro general Augusto Jorge Hughes, comandante em chefe da Força Aérea argentina (Novaro e Palermo, 2003).

6 Essa brecha legal permitiu que, desde 1998, Videla, Massera e outros chefes militares fossem novamente detidos.

7 "Cambiemos", que, em espanhol, significa "Vamos mudar", é uma coalizão de partidos — Proposta Republicana (PRO), Unión Cívica Radical (UCR) e Alianza Cívica (CC-Ari)) - de centro-direita na Argentina que venceu as eleições presidenciais de 2015, com Maurício Macri, do PRO. 0 nome dado à coalizão é uma referência à mudança de projeto político que foi a proposta da campanha eleitoral.

8 Alabarces destaca que a organização Madres de Plaza de Mayo não foi convidada para o evento, que não teve muito apoio, diferente de cinco anos depois, como veremos.

9 Néstor Kirchner faleceu em 2010 e Cristina Kirchner foi reeleita em 2011 para um segundo mandato. Nas eleições de 2015, Cristina não pôde concorrer novamente, pois a lei argentina não permite mais de uma reeleição consecutiva, e seu candidato, Daniel Scioli, terminou derrotado por Mauricio Macri, principal nome da oposição.

10 Por exemplo, o livro El diretor técnico del proceso, dos jornalistas Gasparini e Ponsico, publicado em 1983, como deixa claro o título, associava diretamente Menotti à ditadura, como um integrante do regime no mundo esportivo. 
11 Cesar Luís Menotti, Mundial 78: la historia paralela [DVD], Argentina, 2008.

12 VERRINA, Mariano. "Mario Kempes: el goleador olvidado", texto parte do projeto Papelitos. Disponível em: http://papelitos.com.ar/nota/mario-kempes. Acesso em: 15 set. 2019.

130 partido político Proposta Republicana nasceu exatamente no contexto da crise de 2001-2002, a partir de um think tank, e sempre procurou manter a imagem de outsider na construção de sua imagem pública como partido político (Vommaro, 2014).

140 Arquivo Nacional da Memória, pertencente à Secretaria de Direitos Humanos e Pluralismo Cultural do Ministério de Justiça e Direitos Humanos da Nação, produziu a cartilha digital Ditadura, esporte e memória. Com treze páginas, a publicação dá ênfase à questão da tortura no período ditatorial e às denúncias feitas em função do evento. Apesar de ser uma produção de um órgão diretamente ligado ao governo nacional, a cartilha teve pouca divulgação pública, sem atos envolvendo de forma mais ampla o poder executivo. Disponível em: https://www.argentina.gob.ar/sites/default/files/cuadernillo_mundial_78.pdf.

15 Disponível em: http://papelitos.com.ar/. Acesso em: 20 dez. 2018.

16 "Joguem os papeizinhos, rapaziada!", em tradução livre.

17 "Quiénes somos?". Disponível: em http://papelitos.com.ar/nota/quienes-somos. Acesso em: 25 fev. 2019.

18 VERRINA, Mariano. "El DT de la selección argentina em el Mundial 1978 Menotti: 'Cumplí con mi palavra, hice lo que tenía que hacer'", texto parte do projeto Papelitos. Disponível em: http://papelitos.com.ar/nota/ el-dt-de-la-seleccion-argentina-en-el-mundial-78. Acesso em: 15 set. 2019.

19 VERRINA, Mariano. "Mario Kempes: el goleador olvidado", texto parte do projeto Papelitos. Disponível em: http://papelitos.com.ar/nota/mario-kempes. Acesso em: 15 set. 2019.

20 VERRINA, Mariano. "EI DT de la selección argentina en el Mundial 1978 Menotti: "cumplí con mi palavra, hice lo que tenía que hacer'", texto parte do projeto Papelitos. Disponível em: http://papelitos.com.ar/nota/ el-dt-de-la-seleccion-argentina-en-el-mundial-78. Acesso: em 15 set. 2019.

21 "A 30 años de la final, un homenaje reaviva el debate sobre el Mundial y la dictadura", Clarín, 5 dez. 2008. Disponível em: www.clarin.com/ediciones-anteriores/30-anos-final-homenaje-reaviva-debate-mundial-dictadura_0_BJex0EpRpYx.html. Acesso em: 20 dez. 2018.

22 "La emoción del recuerdo, a 40 años del Mundial 1978", Clarín, 25 jun. 2018. Disponível em: www. clarin.com/deportes/futbol/emocion-recuerdo-40-anos-mundial-1978_0_rJvrk_pbm.html. Acesso em: 20 dez. 2018.

\section{REFERÊNCIAS BIBLIOGRÁFICAS}

FONTES:

Correspondência FIFA - AFA, Arquivo Sede FIFA (Suíça)

Clarín

El País (Espanha) 


\section{El Porteño}

Mundial 78. La Historia Paralela [DVD], Argentina, 2008.

Relatório Final Copa de 1978, Arquivo FIFA, Zurique (Suíça)

www.fifa.com

www.fifamuseum.com

www.memoriaabierta.org.br

http://papelitos.com.ar

\section{Artigos e livros:}

ARCHETTI, Eduardo. Military Nationalism, Football Essentialism, and Moral Ambivalence. In: TOMLINSON, Alan; YOUNG, Christopher (ed.). National Identity and global sports events. Londres: Sunny Press, 2006, p. 133-148.

ALABARCES, Pablo. Fútbol y patria. Buenos Aires: Prometeo Libros, 2008.

CALVEIRO, Pilar. Los usos políticos de la memoria. In: CALVEIRO, Pilar. Sujetos sociales y nuevas formas de protesta en la historia reciente de América Latina. Buenos Aires: Clacso Editorial, 2006.

EISENBER, Christina et al. Fifa (1904-2004): un siglo de fútbol. Madri: Pearsión Educación, 2004.

FRANCO, Marina. Derechos humanos, política y fútbol. Entrepasados (Buenos Aires), v. XIV, n. 28, 2005, p. 27-45.

FRANCO, Marina. La "teoría de los dos demonios": un símbolo de la posdictadura en la Argentina. A Contracorrientes (Buenos Aires), v. 11, n. 2, 2014, p. 22-52.

HALBWACHS, Maurice. Memória coletiva. São Paulo: Centauro, 2006.

JELIN, Elizabeth (comp.) Las conmemoraciones: las disputas en las fechas "in-felices". Madri: Siglo Veintiuno, 2002.

JELIN, Elizabeth. La justicia después del juicio: legados y desafíos en la Argentina postdictatorial. In: FICO, Carlos et al. Ditadura e democracia na América Latina. Rio de Janeiro: FGV, 2008.

JELIN, Elizabeth. Los trabajos de la memoria. Madri: Siglo Veintiuno, 2002.

LVOVICH, Daniel. Sistema político y actitudes sociales en la legitimación de la dictadura militar argentina (1976-1983). Ayer (Buenos Aires), n. 75, 2009, p. 275-299.

MAGALHÃES, Lívia G. Com a taça nas mãos: sociedade, Copa do Mundo e ditadura no Brasil e na Argentina. Rio de Janeiro: Lamparina/Faperj, 2014.

MICHEL, Johann Podemos falar de uma política do esquecimento? Revista Memória em Rede (Pelotas), v. 2-3, ag./nov. 2010.

NOVARO, Marcos; PALERMO, Vicente. Historia Argentina. V. 9. La dictadura militar 1976/1983, del golpe de Estado a la restauración democrática. Buenos Aires: Paidó, 2003.

RICOEUR, Paul. A memória, a história, o esquecimento. Campinas: Editora Unicamp, 2007. 
ROLDÁN, Diego La espontaneidad regulada. Fútbol, autoritarismo y nación en Argentina 78: una mirada desde los márgenes. Prohistoria (Rosario), ano XI, n. 11, 2007, p. 125-147.

SARLO, Beatriz. Tempo passado: cultura da memória e guinada subjetiva. São Paulo: Companhia das Letras/ Belo Horizonte: Editora UFMG, 2007.

VOMMARO, Gabriel. Meterse en política: la construcción de PRO y la renovación de la centroderecha argentina. Nueva Sociedad (Buenos Aires), n. 254, 2014. 